\title{
Schwannoma of Parapharyngeal Space Removed By Transcervical Approach: A Case Report
}

\author{
Ramesh Parajuli*1, Sovit Jung Baral ${ }^{1}$, Rishi Bhatta ${ }^{2}$, Sarita $\mathrm{KC}^{3}$, Binaya wasti ${ }^{4}$ and Utsav Sharma ${ }^{5}$ \\ ${ }^{1}$ Department of ENT, Chitwan Medical college, Nepal \\ ${ }^{2}$ Department of ENT, Nepalgunj Medical college, Nepal \\ ${ }^{3}$ Nepalese Army Institute of Health Sciences, Nepal \\ ${ }^{4}$ Kankai Hospital, Nepal \\ ${ }^{5}$ Norvic hospital, Nepal
}

Submission: April 26, 2017; Published: May 05, 2017

*Corresponding author: Ramesh Parajuli, Department of Otorhinolaryngology, Chitwan Medical College Teaching Hospital, P.O. Box 42, Bharatpur - 10, Nepal, Email: drrameshparajuli@gmail.com

Abbreviations: PPS: Parapharyngeal Space; FNAC: Fine Needle Cytology; CECT: Contrast Enhanced Computed Tomography; MRI: Magnetic Resonance Imaging; SCM: Sternocleidomastoid; HPE: Histo-Pathological Examination

\section{Introduction}

The parapharyngeal space (PPS) belongs to one of the spaces of the deep neck spaces which is a complex anatomical area. Neoplasms of PPS account for only $0.5 \%$ of all head and neck neoplasms [1]. These tumors have different origin histologically such as salivary gland tumor, schwannoma, paraganglioma (vagal or carotid body tumor) and neurofibromas. About $80 \%$ of these tumors in this space are benign while remaining $20 \%$ are malignant in nature [2]. These tumors are usually asymptomatic until they become large and compress nearby structures. Excision of the tumors from this space is a challenge to the Head and neck surgeons as this space contains vital neurovascular structures which may be injured. A case report of schwannoma probably arising from one of the branches of cervical sympathetic chain, which was removed via transcervical approach is presented here.

\section{Case Report}

A 28-year-old male presented to us with the complaint of painless, progressive swelling in the right side of upper neck for 3 years (Figure 1). However, it was not associated with odynophagia, dysphagia, dyspnea or dysphonia. There was no history of trauma. No history of fever, significant weight loss. No restriction of neck movements. No similar swellings in other body parts. His dental history was not significant past medical or surgical history was not significant. On examination there was a diffuse, firm swelling in right upper neck in retromandibular region of neck. It was non tender, smooth surface, ill defined. No local rise of temperature overlying skin was normal. No thrill were felt nor any bruit heard over the swelling. IT was non compressible, non reducible. Transillumination test was negative. There were no visible pulsation above the swelling. The carotid pulsation was present normally. Laryngeal crepitus was present and the trachea was central in position.

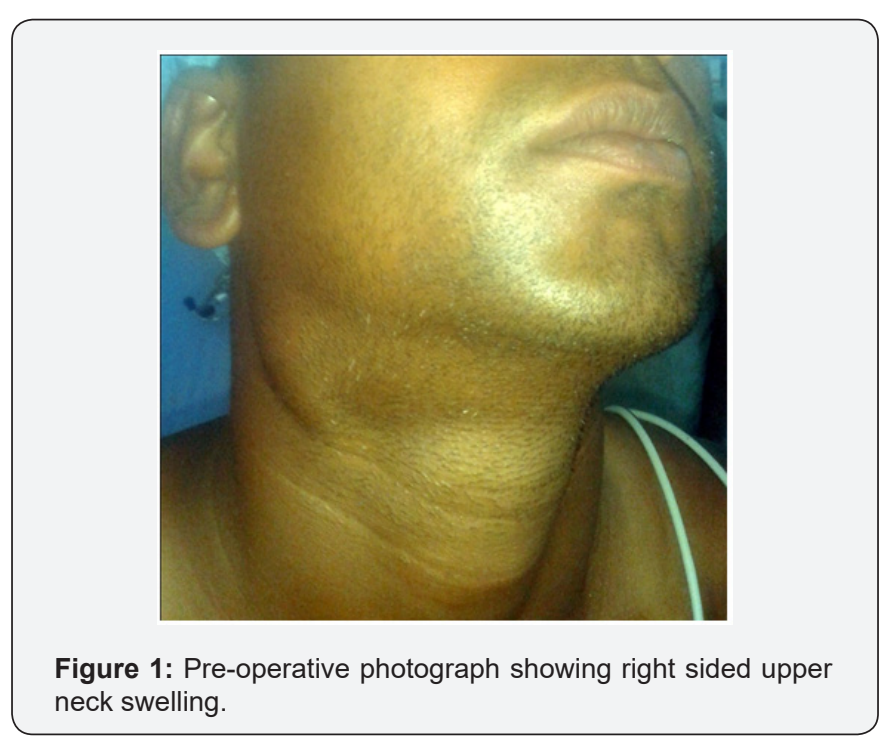




\section{Global Journal of Otolaryngology}

On examination of oral cavity and oropharynx tonsils were normal in position. No any bulge was seen in the lateral and superior wall of oropharynx. The gag reflex was normal. Indirect laryngoscopic examination showed normally mobile vocal cords. Examination of cranial nerves was normal. Based on the history and physical examination a provisional diagnosis of right parapharyngeal mass was made. Ultrasonography suspected it as a tumor of vascular origin. However Fine needle cytology (FNAC) revealed it as a neurogenic tumor. Contrast enhanced computed tomography (CECT) was suggestive of vascular mass in right PPS displacing the carotid artery antero-laterally (Figure 2). Magnetic resonance imaging (MRI) was not done as the patient could not afford it financially. Patient was then planned for sugery. Intraoperatively a horizontal skin incision was made along the skin crease $2 \mathrm{~cm}$ below the angle of mandible extending from midline to the anterior border of sternocleidomastoid (SCM) muscle on right side.
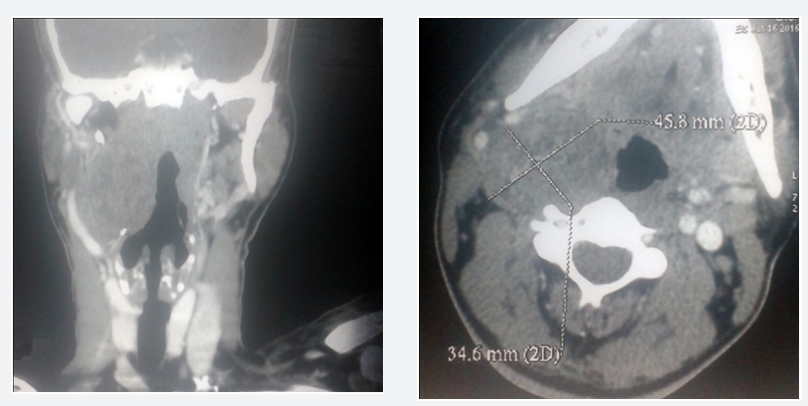

Figure 2: CT scan of neck, coronal and axial views showing well defined mass occupying the PPS.

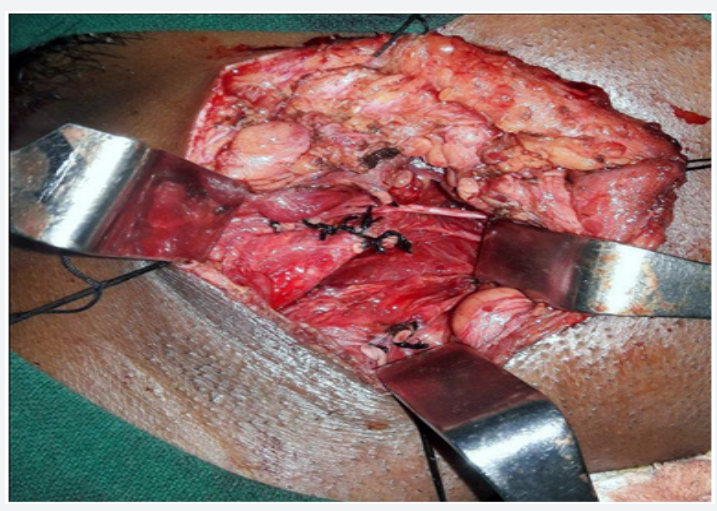

Figure 3: Intra-operative photograph (After excision of mass).

Subplatysmal flaps were elevated both superiorly and inferiorly. Blunt dissection was carried out palpating the mass (Figure 3). The SCM was retracted posteriorly and the carotid vessel was retracted anteriorly. Hypoglossal nerve was retracted superiorly. Vagal nerve was found to be located normal in the posterior compartment of the carotid sheath without any identifiable branch to the mass. However there was a small nerve twig attached to the mass postero-superiorly. There was a potato like encapsulated, oval mass which was freed from all around with finger dissection (Figure 4). On cut section it was homogenous in appearance (Figure 5). Specimen was then sent for histopathological examination (HPE). The patient had uneventful recovery. He was then discharged on 6th post operative day after stitch removal. His HPE report was suggestive of schwannoma of parapharyngeal space.

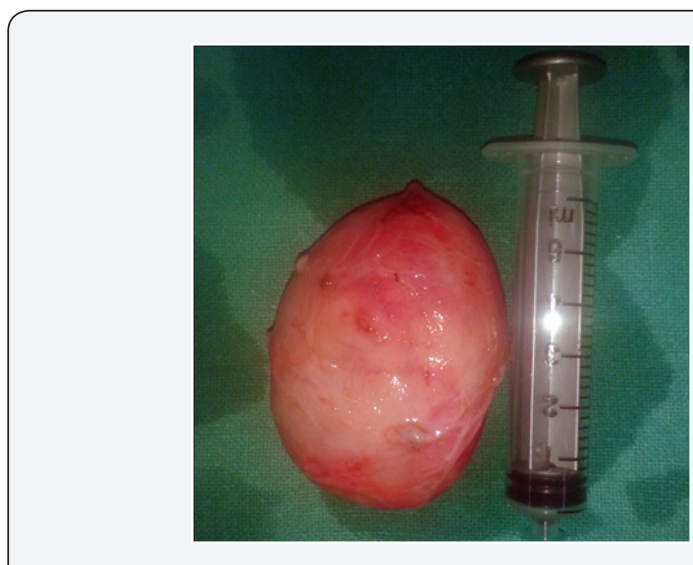

Figure 4: The excised surgical specimen.

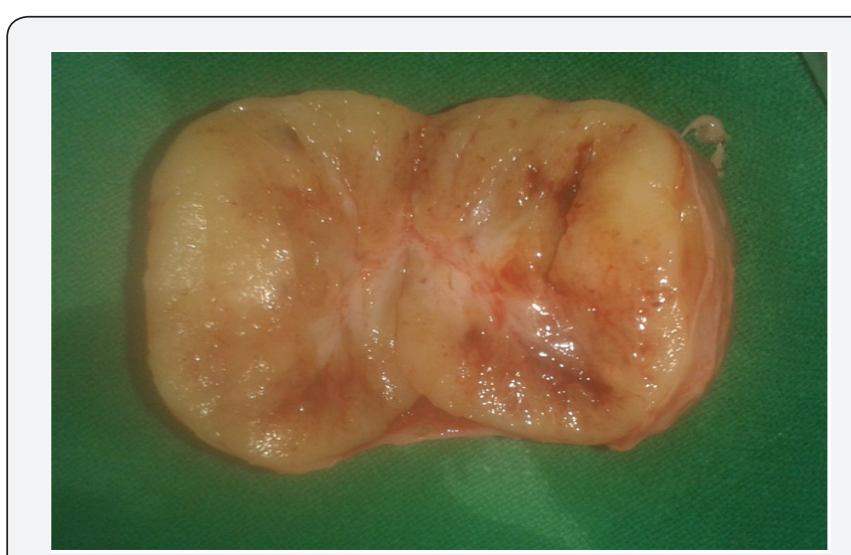

Figure 5: Cut section of the mass.

\section{Discussion}

Parapharyngeal space is a potential space that has a shape of an inverted pyramid. The base of the pyramid is the skull base while the apex is at the greater horn of hyoid bone. The PPS is further divided into 2 compartments these are pre and post styloid compartments. The pre-styloid compartment contains fat, retromandibular portion of the deep lobe of parotid gland,minor salivary gland, ascending pharyngeal artery and pharyngeal venous plexus. The post-styloid compartment contains important neurovascular structures such as internal carotid artery, internal jugular vein, IX,X,XI and XII cranial nerves, cervical sympathetic chain, lymph nodes and glomus bodies.

Usually the patient with PPS lesions is asymptomatic except for a slowly enlarging bulge behind the angle of mouth externally. 
And on examination there can be bulge on the tonsillar pillars and soft palate with pseudo-hypertrophy of tonsil. So it can be misdiagnosed as tonsillar neoplasms and peritonsillitis. Enlarging mass pressing the adjacent cranial nerves gives rise to the symptoms such as nasal blockage, hoarseness, aspiration, dysphagia, dysarthria; and horner syndrome by the pressure on cervical sympathetic chain.

Schwannoma is an uncommon nerve sheath tumor that can arise from any peripheral, cranial or autonomic nerves with the exception of olfactory and optic nerve [3]. Schwannoma of head and neck region frequently arise from vagus and cervical sympathetic chain. The clinical presentation of schwannoma does not have any particular characteristic features. Thus it poses diagnostic dilemma. Investigations advised fro PPS swellings includes USG, FNAC, CT or MRI. Occasionally CT angiography may have to be performed especially when the vascular malformation is suspected. CECT or MRI can well delineate the schwannoma.

Treatment of PPS schwannoma is surgical excision. As the schwannoma is well encapsulated it can completely be removed. There are various approaches for the surgical excision of such masses such as transcervical, transparotid and transmandibular approaches [4]. These approaches can also be used in combination when necessary; such as transparotidtranscervical approach; and addition of mandibulotomy in both the transparotid and transcervical approach to increase the exposure. The aim of different surgical approaches is to provide adequate exposure and to minimize the chances of complications such as neurovascular injuries. The choice of approach is based on the site and size of the tumor; and the surgeon's preference as well. Generally the transcervical approach is used for poststyloid tumors and while the transparotid approach is chosen for pre-styloid tumors.

Transparotid approach is usually used for neoplasms of deep lobe of parotid gland. Superficial parotidectomy is performed initially then the deep lobe tumor is removed by retracting the branches of facial nerve. Mandibulotomy can also be combined with this approach to provide better exposure. In transcervical approach, the submandibular gland is either removed or retracted anteriorly to provide better exposure. Blind finger dissection is commonly done in this approach as this does not give adequate exposure to the neoplasms growing towards skull base superiorly. As like transparotid approach, transcervical approach can also be combined with mandibulotomy. Transmandibular approach uses mandibulotomy at different locations such as body of mandible, angle, ramus, and parasymphyseal mandibulotomy. Complications due to mandibulotomy includes inferior alveolar nerve injury,loss of dentition,malocclusion, malunion or nonunion of mandible. Occasionally it requires a tracheostomy as well.

Before excision of the neurogenic tumors of PPS, the patient should be informed about the possible neurological complications such as injury to cranial nerves VII, IX, X, XI and XII and cervical sympathetic chain. In our case we chose the transcervical approach. Potato like well encapsulate mass was removed in toto. No obvious attachement of the tumor was seen except for a small twig in the postero-superior part. It was probably arising from one of the branches of cervical sympathetic chain. The patient had uneventful recovery. Serious neurological complications such as an injury to cranial nerves VII,IX,X,XI and XII are not uncommon following surgery in the parapharyngeal space [5]. However, our patient did not develop any neurological or vascular complications following excision of the mass. Patient had no complaints and without signs of recurrence on his last follow up 6 months post-operatively.

\section{Conclusion}

Schwannoma of PPS usually presents with the painless, slowly progressive swelling in the upper part of neck which usually does not have any specific clinical features. Preoperative investigation in the form of radio-imaging is very useful in such cases. Complete surgical excision is the treatment of choice which can be done via different surgical approaches. Transcervical approach can be very useful to remove PPS tumors which alone can provide adequate exposure thus avoiding the risk of complications due to mandibulotomy.

\section{References}

1. Batsakis JG, Sneige N (1986) Parapharyngeal and retropharyngeal space diseases. Ann Otol Rhinol Laryngol 98: 320-321.

2. Katre MI, Telang RA (2015) Schwannoma of parapharyngeal space: a case report. Indian Journal of Surgery 77(1): 79-81.

3. Kang GC, Soo KC, Lim DT (2007) Extracranial non-vestibular head and neck schwannoma: A 10 years experience. Ann Acad Med Singapore 36(4): 233-248.

4. Awasti SK, Dutta A (2011) Cervical sympathetic chain schwannoma: A case report. Indian J Otolaryngol Head Neck Surg 63(3): 292-294.

5. Presutti L, Molteni G, Malvè L, Marchioni D, Ghidini A, et al. (2012) Parapharyngeal space tumors without mandibulotomy: our experience. Eur Arch Otorhinolaryngol 269(1): 265-273. 

(C) Commons Attribution 4.0 License DOI: $10.19080 / G J 0.2017 .07 .555713$

\section{Your next submission with Juniper Publishers} will reach you the below assets

- Quality Editorial service

- Swift Peer Review

- Reprints availability

- E-prints Service

- Manuscript Podcast for convenient understanding

- Global attainment for your research

- Manuscript accessibility in different formats

( Pdf, E-pub, Full Text, Audio)

- Unceasing customer service

Track the below URL for one-step submission https://juniperpublishers.com/online-submission.php 